The choice agenda in the Australian supported housing context: A timely reflection

$$
\text { Courtney Wright }^{1^{*}} \text {, Heidi Muenchberger }{ }^{2} \text {, and Jennifer A. Whitty }{ }^{3}
$$

${ }^{1}$ Affiliation: Centre for National Research on Disability Rehabilitation Medicine (CONROD), Griffith University and School of Human Services and Social Work, Griffith Health Institute, Griffith University.

Postal Address: School of Human Services and Social Work, Griffith University, Logan Campus, University Drive, Meadowbrook, QLD 4131, Australia.

Telephone: +61 733821112

Email: Courtney.wright@griffith.edu.au

*Corresponding Author

${ }^{2}$ Affiliation: Centre for National Research on Disability Rehabilitation Medicine (CONROD), Griffith University and School of Human Services and Social Work, Griffith Health Institute, Griffith University.

Postal Address: School of Human Services and Social Work, Griffith University, Logan Campus, University Drive, Meadowbrook, QLD 4131, Australia.

Telephone: +61 733821229

Email: h.muenchberger@griffith.edu.au

${ }^{3}$ Affiliation: School of Medicine, Griffith Health Institute, Griffith University and School of Pharmacy, The University of Queensland.

Postal Address: School of Pharmacy, Pharmacy Australia Centre of Excellence, The University of Queensland, St Lucia Campus, Level 4, 20 Cornwall Street, Woolloongabba, QLD 4102, Australia.

Telephone: +61733461900

Email: j.whitty@uq.edu.au

Affiliation of research conducted: Griffith Health Institute, Griffith University

Funding Acknowledgements: This work is funded by The Department of Science, IT, Innovation and the Arts (DSITIA) on behalf of the Queensland Government under Grant 42323 (Smart Futures Fellowship Program). 


\section{The choice agenda in the Australian supported housing context: A timely reflection}

\section{Points of Interest}

- For younger adults with a neurological disability, relocation back to the family home or placement in a group home or care facility - where these settings are not their preferred living environment - is a depressing, and isolated experience that represents a loss of independence, autonomy, control and choice.

- In response to the increasingly recognised importance of consumer housing choice for all people with disabilities, the Disability sector and the Housing and Construction sector have been key drivers of movements to translate housing choice policy into practice in Australia. However, a disconnection between housing choice policy and practice has remained.

- With the lack of suitable, long-term residential options for people with disability remaining a significant issue in Australia, this timely contribution to the field highlights the need to develop innovative housing design alternatives that are based on user housing priorities and preferences, and conducive to a person's physical, psychological and social health. 


\title{
The choice agenda in the Australian supported housing context: A timely reflection
}

\author{
Abstract \\ The last thirty years has seen significant developments in the Australian housing sector for \\ people with disabilities. Despite much change in the sector, and advancements in disability \\ services, the range of current supported housing options for younger Australian adults with a \\ neurological disability remains vastly under-developed. This is despite a widely accepted and \\ endorsed recognition that, as is the general population, people with all forms of disability \\ have a right to housing of their choice. This paper presents a timely critique of the key actions \\ made by the Australian disability and housing sectors and subsequently proposes a more \\ informed approach to supported housing design and development: one that is based on a \\ comprehensive understanding of consumer housing priorities and preferences, and is \\ conducive to a person's biopsychosocial health.
}

Keywords: Housing policy; housing design; housing choice; physical disability; cognitive disability 


\section{The choice agenda in the Australian supported housing context: A timely reflection}

\section{Introduction}

It is widely acknowledged that adults with acquired brain or spinal injury or progressive neurological illness (e.g., Multiple Sclerosis; Cerebral Palsy) incur significant housing challenges post diagnosis (Cameron, Pirozzo, and Tooth 2001; Foster, Fleming, and Tilse 2007; Nalder et al. 2012). Due to the complex physical and/or cognitive nature of their condition, individuals living with a neurological disability often require assistance with activities of daily living (ADL) and personal care. This has direct implications on the type of housing they require in the long-term, and differentiates their housing need from other disability types. The housing challenges experienced are reflective of a broader and persistent issue relating to housing availability as well as the problem with housing suitability. In the case of acquired neurological injury, once the person is deemed medically stable by a physician or able to function semi-independently, arrangements are made to refer the person back to: (a) their family home, where the infrastructure often requires modifications; or (b) some form of supported accommodation or residential care facility (in instances where the family home is not an option) to continue their care and support as needed during this initial recovery period (Beer and Faulkner 2008; Cameron, Pirozzo, and Tooth 2001; Foster, Fleming, and Tilse 2007; Nalder et al. 2012). Similarly, adults living with a neurological disability or progressive illness since birth or childhood often reside in the family home much longer than a person of similar age without a disability (Australian Bureau of Statistics 2009). This is, in part, due to the lack of suitable housing alternatives currently available to support the person in living away from family.

Whether the person's neurological disability is acquired or developmental in nature, individuals are usually faced with two scenarios relating to their long-term housing situation: 
(1) stay at home with family indefinitely, though this often increases pressure on families and may not be the person’s preferred option (Beer and Faulkner 2009; Buhse 2008; Carnes and Quinn 2005; Harrell, Kassner, and Figueiredo 2011); or (2) move out of the family home into physically accessible social housing that is typically managed by government housing departments and housing services (Beer and Faulkner 2009; Saugeres 2011). Group homes are the dominant housing model under this scenario, due to cost efficiencies and the lack of physically accessible housing stock. Sadly, private housing is often not an option for those with a physical disability, due to its physically inaccessible or unaffordable nature (Australian Housing and Urban Research Institute 2007; Australian Network for Universal Housing Design and RI Australia 2014; Robst, Deitz, and McGoldrick 1999; Saugeres 2011). For younger adults aged under 65 years (i.e., pre-retirement age and therefore considered 'too young' to occupy residential aged care), a prolonged stay or relocation back to the family home, or placement in a group home or care facility - where these settings are not their preferred living environment - is a depressing, and isolated experience that represents a loss of independence, autonomy, control and choice (Bostock and Gleeson 2004; Cameron, Pirozzo, and Tooth 2001).

While more contemporary, individualised, supported living options may be more appropriate for the person and their family, supported living dwellings are often not readily available or physically accessible for younger adults with a neurological disability. Further, there is little evidence currently available to support their use. This is due to much of the existing literature: (a) focussing on traditional group home models or cluster settings at the expense of other design alternatives; and (b) failing to provide 'strong' evidence regarding the impact different housing models have on resident outcomes (Callaway et al. 2013; Winkler, Farnworth, Sloan, and Brown 2011). This lack of information has, in part, supported (by not challenging) the 'one-size-fits-most' near-monopoly market currently occurring in 
parts of Australia. The near-monopoly market describes an over-reliance on the traditional group home model (outside of the family home) by the State, non-government organisations (NGOs) and not-for-profit housing agencies, which has resulted in limited housing design alternatives (see Figure 1). Although it has been reported that there is no single or 'one size fits all' housing solution (Sloan et al. 2012; Taleporos et al. 2013), consumers and disability advocates have strongly championed the need for greater choice when it comes to their housing options. 
Running Head: THE CHOICE AGENDA IN AUSTRALIAN SUPPORTED HOUSING

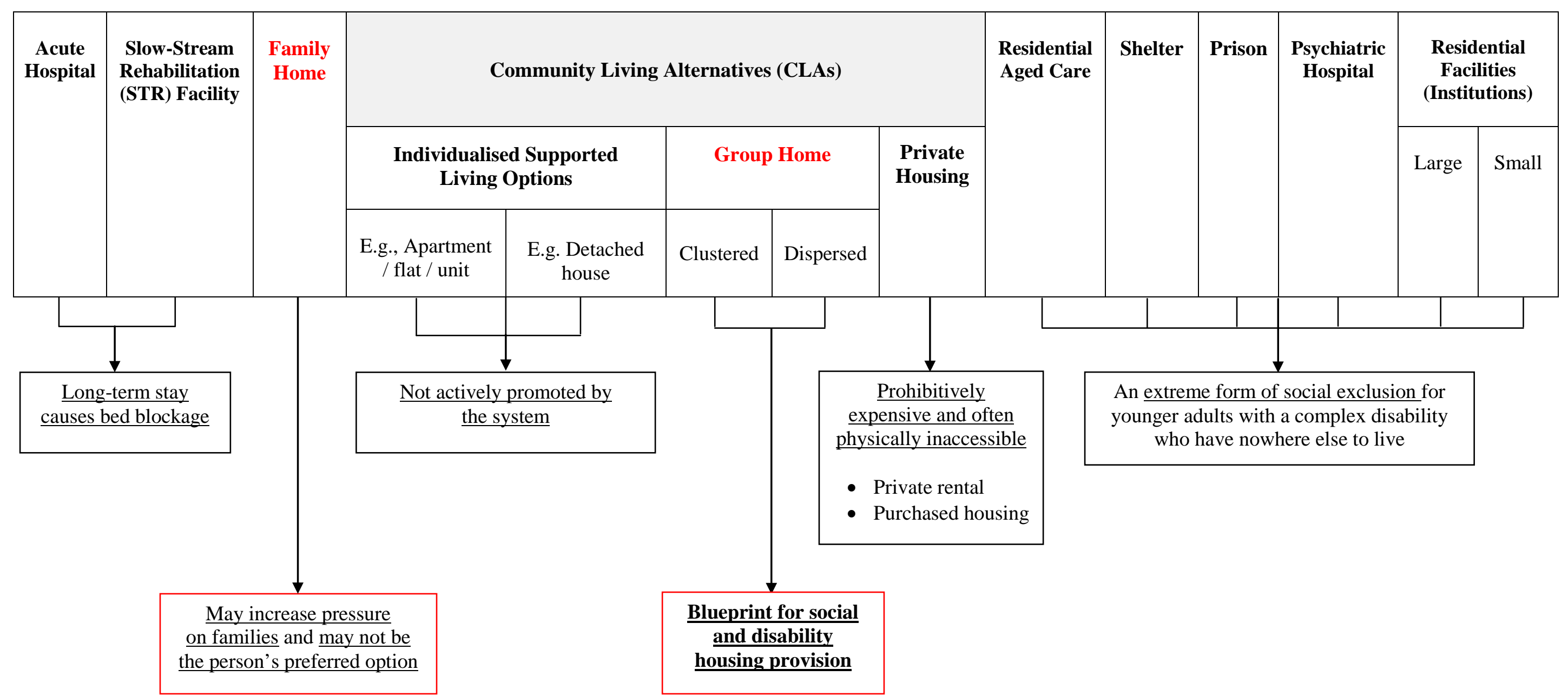

Figure 1. A snapshot of existing housing models available to younger adults with complex disabilities in Australia (Australian Network for Universal Housing

Design and RI Australia 2014; Beer and Faulkner 2008; Bostock and Gleeson 2004; Carnes and Quinn 2005; Wiesel 2011; Winkler, Farnworth, Sloan, Stringer

et al. 2011) 
In response to the increasingly recognised importance of consumer housing choice in Australian political and legislative narratives for all people with disabilities ${ }^{1}$, two sectors have been key drivers of movements to translate choice policy into practice: (1) The Disability sector, and (2) the Housing and Construction sector. Indeed, the Disability sector has reframed and redefined the nature, provision and financing of social services provided to individuals with a disability (Foster et al. 2012) with movements such as decentralisation of the disability service system and an increased focus on person-centred service delivery. With similar intent, the Housing and Construction sector has responded to the choice agenda by focussing on housing design for people with physical accessibility needs: the introduction of international Universal Housing Design guidelines (Australian Institute of Health and Welfare [AIHW] 2011; Commonwealth of Australia 2009; Livable Housing Australia 2012; NSW Department of Ageing, Disability and Home Care 2009; PricewaterhouseCoopers [PwC] 2011). Although these initiatives align with the aspirations and desires of individuals with disabilities to increase their choice and control over their own residential arrangements, a disconnection between housing choice policy and practice has remained.

The current article presents an informed insight into the Australian housing choice agenda, and identifies the implications of this agenda for younger adults with a neurological disability. As will be shown, a number of factors have determined individuals’ living situation, including challenges regarding policy implementation, failure to penetrate market mechanisms to stimulate greater accessible housing, and the absence of a comprehensive

\footnotetext{
${ }^{1}$ E.g., Australia's ratification of the United Nations Convention on the Rights of Persons with Disabilities (UNCRPD; United Nations 2006), the National Disability Agreement (Council of Australian Governments, 2012) [Commonwealth], the Disability Discrimination Act 1992 [Commonwealth]; the Disability Services Act 1986 [Commonwealth], the National Disability Insurance Scheme Act 2013 [Commonwealth], and the Guardianship and Administration Act 2000 [State of Queensland]
} 
approach to housing provision that systematically involves consumers in early design processes. With the lack of suitable, long-term residential options remaining a significant issue in Australia (Commonwealth of Australia 2009), this timely contribution to the field highlights the need to develop innovative housing design alternatives that are: (a) based on user housing priorities and preferences; and (b) conducive to a person's biological (physical), psychological and social (often termed 'biopsychosocial') health. To place the housing choice agenda into context, the systemic and community factors contributing to supported housing outcomes in Australia will first be discussed.

\section{Systemic and community factors contributing to housing outcomes}

As the group home model has emerged (post-deinstitutionalisation ${ }^{2}$ ) as the blueprint underpinning Australian social and disability housing, group home placement is particularly likely for younger adults with a neurological disability wishing to live in the community. Indeed, there is evidence to suggest the group home model can lead to good social participation and quality of life (QOL) outcomes for residents with a severe or profound disability (see Clement and Bigby 2010; Felce 1989; Kozma, Mansell, and Beadle-Brown 2009; Lamontagne et al. 2013; Mansell et al. 1987; Sloan et al. 2012). However, research also suggests outcomes are variable and dependent primarily on the person's adaptive skills and degree of disability, the staff practices implemented, and the culture developed both within the dwelling and service organisation as a whole (Bigby 2012; Bigby et al. 2012; Clement and Bigby 2010, 2012; Kozma et al. 2009; Mansell et al. 2008; Quarterly Brain Injury Services Meeting (QBISM) Group 2013). For example, poor staff and organisational

\footnotetext{
${ }^{2}$ Deinstitutionalisation refers to the active removal of people with disabilities from large institutional facilities into the community since the 1980s. Although not discussed here, deinstitutionalisation led to major reforms in Australian community residential services and supports.
} 
practices that employ a custodial approach to service delivery rather than an approach that places the person in the centre (and in control) of their living arrangements has been described as creating 'a smaller-scale version of the large residential institutions of the past' (Mansell 2009, p. 12). In addition, the group home model is viewed by some younger adults with a neurological disability as an 'only option’ or a stepping-stone to independent (supported) living. Thus, the group home model is not preferred by everyone (Bergmark, Winograd, and Koopman 2008; Ownsworth et al. 2004). What remains is a dominant housing model that when managed well, has the potential to deliver positive outcomes for younger adults with a neurological disability. However, given its current dominance in the market, the consumer is unable to choose an alternative housing model if desired because few (validated) options exit (QBISM Group 2013).

A combination of systemic circumstances has resulted in an overreliance on the group home model in Australian social and disability housing at the expense of other design alternatives. First, a shortage in the supply of physically accessible dwellings in both the private and public housing sectors (Australian Network for Universal Housing Design and RI Australia 2014; Saugeres 2011) combined with cost-efficiencies (i.e., economies of scale) has fostered collective living arrangements. It is not uncommon for people with a similar degree of physical and/or cognitive disability, and therefore similar level of care needs, to have been grouped together to share their housing support packages and staff (Bostock et al. 2001;

Taleporos et al. 2013). The combination of these circumstances has resulted in a crisis-driven, needs-based, vacancy allocation system that seems more service determined than consumerdriven. As Wiesel and Fincher (2009) highlight, the rhetoric of housing choice appears to have transpired as a principal concept after community-based models had already become standard in Australian disability services (post-deinstitutionalisation). 
Societal factors have also contributed to residents’ housing outcome. For instance, the prejudicial attitudes of some local community members regarding the nature of disability facilities and the people who use them have resulted in some neighbourhoods opposing housing for people with disabilities in their area (Bostock and Gleeson 2004; Wiesel and Fincher 2009). While this intolerance has not prevented the State, NGOs, or not-for-profit housing agencies building some physically accessible dwellings in central locations, it is possible these prejudicial attitudes of some (not all) local residents has made community integration for younger adults with a neurological disability difficult. As Winkler, Farnworth, Sloan, and Brown (2011) suggest, being physically located within a community does not necessarily result in community participation: 'Assisting people with high care and complex needs to be included in the mainstream of society is a challenging area of work that requires tenacity because relationships are not always spontaneously formed’ (p. 161). This situation suggests considerations for suitable, long-term housing options must extend beyond the dwelling itself, and consider residents’ location and neighbourhood context.

\section{The Australian disability sector: Response to choice policy Decentralisation movement}

Historically, Australia has attempted to enact greater consumer choice and control (and less centralised responsibility) for people with disabilities through: (a) outsourcing housing and support services to the not-for-profit sector, and (b) separating housing and support services to safeguard vulnerable individuals. According to Wiesel and Fincher (2009), these initiatives aimed to increase the range and quality of services available to consumers by challenging the monopoly of service provision held by the State. The initiatives also aimed to enhance consumer choice by promoting competition amongst service providers rather than Governments being responsible for and facilitating a 'one-stop-shop' for housing and support 
(Wiesel and Fincher 2009). However, implementation of both decentralisation initiatives have had little impact in increasing consumer housing choice, especially for younger adults with a neurological disability (Bigby and Ozanne 2001; Bostock and Gleeson 2004; MacKinnon and Coleborne 2003; Wiesel and Fincher 2009).

Although it is likely that there are a number of individual agencies providing quality accommodation for adults with complex disabilities, 'new' housing models developed through outsourcing are at risk of maintaining institutional practices and structures (Bigby 2012; Bostock and Gleeson 2004; Mansell et al. 2008; QBISM Group 2013). Most importantly, consumers have had limited systematic and early input in developing innovative housing design that goes beyond meeting their physical accessibility needs (Commonwealth of Australia 2009; Heywood 2004; Imrie 2004; King 1996).

Further, disability agencies have tended to focus on the nature of social, financial and therapeutic supports required by individuals living in the community rather than the built environment residents will call 'home’ (Bostock and Gleeson 2004; Muenchberger et al. 2012; Wiesel 2011). This service approach reflects a lack of collaboration and communication between different providers and highlights the silos under which the Australian disability and housing sectors have continued to operate (Bostock and Gleeson 2004; Foster et al. 2012; Parker and Fisher 2010; State of Victoria, Department of Human Services 2003).

\section{Person-centred practice and its impact on housing}

Widely accepted as best practice (Sanderson, Thompson, and Kilbane 2006), a personcentred approach places the person with disability at the centre of decision-making when it comes to the supports and services they use. Rather than regarding independence as physical capacity to carry out particular tasks or intellectual capacity to understand existing options (or to express a preference), person-centred service delivery views independence more broadly in 
terms of having choice and control (Morris 2004; Wiesel and Fincher 2009). While shifting the balance of power from professionals and agencies to the person (see Table 1), people with disabilities are provided individualised assistance and support to make an informed choice (National Insurance Disability Scheme Act 2013, NSW Department of Ageing, Disability and Home Care 2009; Wiesel and Fincher 2009). The translation of person-centred policy into practice is evidenced by the current emphasis on individualised support plans and funding packages (also referred to as 'direct payments') in the National Disability Insurance Scheme (NDIS) to be rolled out in full across Australia by 2019. 
Table 1. A comparison between traditional and contemporary approaches to supported housing

Traditional Approaches

\begin{tabular}{|c|c|c|}
\hline Strengths- & Focuses on individual from a & Focuses on individual's unique \\
\hline \multirow[t]{5}{*}{ based } & disability professional & interests and preferences \\
\hline & viewpoint & \\
\hline & Commences from a deficit and & Builds on strengths and high \\
\hline & needs basis and low & expectations that everyone can and \\
\hline & expectations & should enjoy the 'good' life \\
\hline Future & Looks to what is currently & Offers beyond what is currently \\
\hline \multirow[t]{2}{*}{ oriented } & available from a service & available and works towards the \\
\hline & & future \\
\hline Natural & Planning assumes the person & Focuses on organising \\
\hline \multirow[t]{3}{*}{ supports } & will spend most of their time & individualised, natural and creative \\
\hline & grouped with other people with & supports and reduces reliance on the \\
\hline & disability & service system \\
\hline Service & Situates power with the & Situates power and control with the \\
\hline \multirow[t]{3}{*}{ relationship } & professionals & person and their allies \\
\hline & Fits the person into the service & Tailors supports to achieve the \\
\hline & & person's goals and future \\
\hline \multirow[t]{2}{*}{ Participation } & Largely limits the person to & Aims for social inclusion, valued \\
\hline & disability specialist programs & roles and community participation \\
\hline
\end{tabular}

*Adapted from NSW Department of Ageing, Disability and Home Care (2009) 


\section{Individualised support plans and funding packages}

Individualised support plans and funding is advocated as a means for service users to determine their own housing and support packages. In this way, funding is attached to the individual instead of a service agency, allowing the person to 'choose for themselves the type of housing that they want (and can afford) and the types of supports they wish to use within the range of available options, just as any other member of the community' (Sach and Associates 1991, 8, cited in Bostock and Gleeson 2004). While the promotion of individualised support plans and funding does embody a shift in control from the professionals to the person, cost ceilings have previously prevented some individuals from receiving the level of funding they require to be supported in the home of their choice (Lord and Hutchison 2003; Morris 2004).

Specifically, the direct payment initiative in Victoria, Australia (prior to the commencement of the national NDIS scheme) was seen to be more successful in increasing housing choice for people with lower support needs over those with more complex support needs. An example from Victoria highlighted the larger funding packages offered to those with lower levels of support need to assist them in moving out of groups homes, to allow more people with high support needs to move in (Wiesel and Fincher 2009). Younger adults with a complex disability were therefore at risk of continued categorisation into specific housing models - the group home - even with individualised funding policies in place. Given that the NDIS is currently being trialled in sites across Australia, further research is needed to evaluate the impact individualised support plans and funding packages (under the NDIS scheme) have had on increasing consumer housing choice, especially for younger adults with a neurological disability. 


\section{The Australian housing and construction sector: Response to choice policy Promotion of universal housing design principles and guidelines}

With the number of individuals living with a disability viewed as a 'minority' population in Australia, the physical design of most dwellings does not cater to the needs of individuals who sit 'outside the norm’ According to Imrie (2004, 685),

The physical design of dwellings is not well suited to [the] needs [of people with physical disabilities] for access into, and ease of movement about and use of, domestic spaces. Rather, most domestic design is premised on the production of dwelling spaces to facilitate use by people without bodily impairments.

Existing mainstream housing stock (i.e., villas, apartments, private rental, purchase housing) therefore prevents many younger adults with a physical disability from physically accessing more individualised accommodation. This situation directly contributes to the shortage of suitable housing stock in Australia, impacting consumer housing choice by limiting the number and variety of potential dwellings that may accommodate individuals. This housing shortfall has significant repercussions for the 'minority' population, given that roughly 4 million Australians, or $20 \%$ of the population have a disability and nearly 1.3 million people have a profound or severe disability (PwC 2011, 11; AIHW 2013).

In joining with international trends, Australian governments began producing and implementing design guides, codes of practice and/or statutes based on the seven Principles of Universal Design (applied to housing; see Appendix A) to guide the production of more physically accessible dwellings. In the absence of a national focus however, Australian State, Territory, and Local governments and councils had established inconsistent Universal Housing Design guidelines (Office of the Public Advocate - Queensland 2005; Saugeres 2011). Subsequently, the Australian Government committed \$1 million seed funding over three years (2011-12 to 2013-14) to support the Livable Housing Design Initiative. This 
national framework aims for all new residential dwellings across Australia to be of an agreed Livable Housing Design standard by 2020 (Australian Government Department of Families, Housing, Community Services and Indigenous Affairs 2010; Livable Housing Australia 2012).

Due to a perceived lack of consumer demand however, the voluntary nature of the Livable Housing Design guidelines has been met with resistance to implement by the Housing and Construction sector (Australian Network for Universal Housing Design and RI Australia 2014). In May 2014, approximately 294 new dwellings were registered as having been built to Universal Housing Design specifications. This is in stark contrast to the agreed target: 25\% of all new residential dwellings (approximately 35,000 dwellings) by 2013 (Australian Network for Universal Housing Design and RI Australia 2014). This slow uptake by the Housing sector has meant a greater number (and variety) of physically accessible dwellings remain unavailable to younger adults with a physical disability. This situation therefore perpetuates the reliance of younger adults with a neurological disability on the State, NGOs and not-for-profit housing agencies for housing and support.

As confirmed by the Social Determinants of Health and Environmental Health Promotion Framework (Schulz \& Northridge 2004), multiple factors within the broader built environment influence residents' biopsychosocial health and wellbeing. Despite the intuitive benefits of a nationally recognised accessibility design standard, the use of Livable Housing Design guidelines is limited because of the narrow focus on the functional (i.e., physical accessibility) aspects of the dwelling and lack of attention to broader behavioural and psychological impacts of place, which is now well reported in research (see Carr et al. 2011; Clark and Kearns 2012; Curtis et al. 2007; Dyck et al. 2005; Kyle and Dunn 2008; Muenchberger et al. 2012; Shultz and Northridge 2004; Wister 2005). The following examples highlight the important contextual factors that research suggests should also be 
considered in a more comprehensive approach to housing: (1) information regarding additional housing design features (beyond physical accessibility) that might improve residents' 'social, psychological, spiritual ... and behavioural components of health ... [necessary for the] stimulation of healing and the achievement of wholeness' (Jonas and Chez 2004, S1; Imrie 2006); (2) the social and care environment (i.e., appropriate tenancy arrangements; non-family paid carer characteristics; nature of support packages; care design features that promote efficiency of care; Parker et al. 2004; Ulrich 2000, 2006; Young People in Nursing Homes National Alliance and Monash University 2014) for individual residents; (3) housing affordability and tenure (Johnson, Parkinson, and Parsell 2012; Tsemberis, Gulcur, and Nakae 2004; Victorian Coalition of ABI Service Providers Inc 2014; Wiesel and Fincher 2009); and (4) community participation and access (Dyck et al. 2005; Schulz and Northridge 2004; Wagemakers et al. 2010; Young People in Nursing Homes National Alliance and Monash University 2014).

\section{A new way forward: A consumer-driven, environmental approach to innovative supportive housing design and development}

Despite a commitment to the internationally renowned United Nations Convention on the Rights of Persons with Disabilities (United Nations 2006), widely endorsed legislation, a significant restructure of the social and disability service system, as well as a push for national Universal Housing Design guidelines, Australian adults with complex disabilities have been inadvertently disadvantaged by the housing agenda (Wiesel and Fincher 2009).

Although Australian authorities recognise the importance of providing alternative housing models (choice) to consumers with a disability, a combination of circumstances has prevented authorities from implementing innovative housing design and alternative housing models for this population. These circumstances include: 
1. A continued shortage of physically accessible housing stock;

2. Cost efficiencies related to communal living;

3. Limited evidence regarding the impact of different housing models on resident outcomes; and

4. The absence of a comprehensive approach to housing that conceptualises consumer priorities and preferences in relation to broader contextual determinants of health and wellbeing (e.g., psychological, physical, emotional and social health). Such a framework would guide the development of innovative housing design alternatives that are not only based on consumer needs and wishes, but that are also conducive to a person's wellbeing.

To address the shortage of physically accessible housing stock, a number of advisory authorities have called for universal housing design guidelines to be mandated and regulated to ensure implementation (Australian Network for Universal Housing Design and RI Australia 2014; Disability Investment Group 2009; Queensland Action for Universal Housing Design n.d.). While increasing the number of physically accessible dwellings is needed in Australia, addressing physical access issues forms only part of, rather than the whole, of the improved housing picture. According to Heywood (2004), a 'full understanding' of the needs and experiences of consumers is imperative in any residential design and development process. Consistent with person-centred planning, the user must be at the centre of the approaches to innovative housing design and be driving that process.

A contemporary approach to new housing development therefore requires a change to the current model so that the voices of consumers are no longer incorporated superficially into design processes. Thus, person-centred approaches recognize that developing innovative housing design to address the residential needs of people with disability is best met by the consumers themselves (Williamson 2006). One way to meaningfully engage consumers in 
developing innovative housing design is to systematically investigate their housing priorities and preferences. Demonstrating the goods or services consumers prioritize is better able to inform market decisions around viability and consumer value than an approach broadly asking individuals what they 'want'.

In addition, new housing initiatives in disability ought to consider a person's biopsychosocial needs, indeed as an integration of components rather than separate entities (Antonovsky 1996; Eriksson and Lindström 2008). As an environmental lens to residential development recognises that there are physical, psychological and social components of environments and that these elements interact to affect the biopsychosocial health of individuals (Wister 2005), consumer priorities and preferences ought to be guided by an environmental approach to housing development to ensure innovation does not compromise residential quality. An environmental approach to housing for people with disabilities would integrate considerations regarding the design of the dwelling, its location, and neighbourhood context across the person’s built, social, and care environment. Investigating consumer priorities and preferences underpinned by such an approach would redefine the minimum standard of housing for people with disabilities. Indeed, this improved standard would likely ensure the future development or re-development of housing alternatives are meaningful to users, market-relevant and be of a standard conducive to biopsychosocial health and wellness. 


\section{References}

Antonovsky, A. 1996. “The Salutogenic Model as a Theory to Guide Health Promotion.” Health Promotion International 11 (1): 11-18. doi: 10.1093/heapro/11.1.11

Australian Bureau of Statistics. 2009. "Home and Away: The Living Arrangements of Young People”. No. 4102.0. Available from http://www.ausstats.abs.gov.au/ausstats/subscriber.nsf/LookupAttach/4102.0Publicati on30.06.096/\$File/41020_Homeandaway.pdf

Australian Government Department of Families, Housing, Community Services and Indigenous Affairs. 2010. “National Dialogue on Universal Housing Design: Strategic Plan.” Available from http://www.fahcsia.gov.au/sites/default/files/documents/05_2012/national_dialogue_s trategic_plan.pdf

Australian Government Department of Families, Housing, Community Services and Indigenous Affairs. 2013. “Fact Sheet Supported Accommodation Innovation Fund (SAIF).” Available from

http://www.dss.gov.au/sites/default/files/documents/07_2013/saif_factsheet_2013.pdf Australian Housing and Urban Research Institute (AHURI). 2007. "Supporting the Housing of People with Complex Needs”. AHURI Research and Policy Bulletin, Issue 90. Melbourne, Victoria: AHURI.

Australian Institute of Health and Welfare (AIHW). 2011. "Housing Assistance in Australia 2011”. Cat. No. HOU 236. Canberra, ACT: AIHW.

Australian Institute of Health and Welfare (AIHW). 2013. “Australia's Welfare: 2013”. Australia’s Welfare Series No. 11. Cat No. AUS 174. Canberra: Australian Government. 
Australian Network for Universal Housing Design and RI Australia. 2014. "Report on the Progress of the National Dialogue on Universal Housing Design 2010-2014.” Place of publication unknown: Authors.

Beer, A., and D. Faulkner. 2009. “The Housing Careers of People with a Disability and Carers of People with a Disability.” Australian Housing and Urban Research Institute Research Report. Melbourne, Victoria: AHURI.

Bergmark, B. A., C. H. Winograd, and C. Koopman. 2008. "Residence and Quality of Life Determinants for Adults with Tetraplegia of Traumatic Spinal Cord Etiology.” Spinal Cord 46 (10): 684-689. doi: 10.1038/sc.2008.15

Bigby, C. 2012. "Social Inclusion and People with Intellectual Disability and Challenging Behaviour: A Systematic Review.” Journal of Intellectual and Developmental Disability 37 (4): 360-374. doi: 10.3109/13668250.2012.721878

Bigby, C., M. Knox, J. Beadle-Brown, T. Clement, and J. Mansell. 2012. “Uncovering Dimensions of Culture in Underperforming Group Homes for People with Severe Intellectual Disability.” Intellectual and Developmental Disabilities 50 (6): 452-467. doi:10.1352/1934-9556-50.06.452

Bigby, C., and E. Ozanne. 2001. "Shifts in the Model of Service Delivery in Intellectual Disability in Victoria.” Journal of Intellectual \& Developmental Disability 26 (2): 177-190. doi:10.1080/13668250020054495

Bostock, L., and B. Gleeson. 2004. “Contested Housing Landscapes? Social Inclusion, Deinstitutionalisation and Housing Policy in Australia.” Australian Journal of Social Issues 39 (1): 41-62. Available from http://search.informit.com.au.libraryproxy.griffith.edu.au/documentSummary;dn=837 724847735052;res=IELHSS 
Bostock, L., B. Gleeson, A. McPherson, and L. Pang. 2001. “Deinstitutionalisation and Housing Futures: Final Report.” Australian Housing and Urban Research Institute Research Report No. 2 of the Final Report Series. Available from http://www.ahuri.edu.au/publications/projects/p70015

Buhse, M. 2008. “Assessment of Caregiver Burden in Families of Persons with Multiple Sclerosis.” Journal of Neuroscience Nursing 40 (1): 25-31.

Callaway, L., D. Winkler, S. Sloan, L. Pattuwage, W. Osborn, and V. Pitt. 2013. “Models of Supported Accommodation for People with Traumatic Brain Injury: A Systematic Review.” Melbourne, Victoria: Institute for Safety, Compensation and Recovery Research.

Cameron, C., S. Pirozzo, and L. Tooth. 2001. “Long-Term Care of People below Age 65 with Severe Acquired Brain Injury: Appropriateness of Aged Care Facilities.” Health and Health Care 25 (3): 261-264. doi: 10.1111/j.1467-842X.2001.tb00574.x

Carnes, S. L., and W. H. Quinn. 2005. “Family Adaptation to Brain Injury: Coping and Psychological Distress.” Families, Systems, \& Health 23 (2): 186-203. doi:10.1037/1091-7527.23.2.186

Carr, V. L., D. Sangiorgi, M. Büscher, S. Junginger, and R. Cooper. 2011. “Integrating Evidence-Based Design and Experience-Based Approaches in Healthcare Service Design.” Health Environments Research \& Design Journal 4 (4): 12-33. Available from http://search.proquest.com.libraryproxy.griffith.edu.au/docview/894513501

Clement, T., and C. Bigby. (Eds) 2010. “Group Homes for People with Intellectual Disabilities.” London, UK and Philadelphia, PA, USA: Jessica Kingsley Publishers

Clement, T., and C. Bigby. 2012. “Competencies of Front-Line Managers in Supported Accommodation: Issues for Practice and Future Research.” Journal of Intellectual and Developmental Disability 37 (2): 131-140. doi: 10.3109/13668250.2012.681772 
Clark, J., and A. Kearns. 2012. “Housing Improvements, Perceived Housing Quality and Psychosocial Benefits from the Home.” Housing Studies 27 (7): 915-939. doi:10.1080/02673037.2012.725829

Commonwealth of Australia. 2009. "Shut Out: The Experience of People with Disabilities and their Families in Australia. National Disability Strategy Consultation Report.” Canberra, ACT: Commonwealth of Australia.

Council of Australian Governments. 2012. “National Disability Agreement.” Available from http://www.federalfinancialrelations.gov.au/content/npa/disability/nationalagreement.pdf

Curtis, S., W. Gesler, K. Fabian, S. Francis, and S. Priebe. 2007. “Therapeutic Landscapes in Hospital Design: A Qualitative Assessment by Staff and Service Users of the Design of a New Mental Health Inpatient Unit.” Environment and Planning C: Government and Policy 25 (4): 591-610. doi:10.1068/c1312r

Disability Discrimination Act 1992, No. 135. 1992. Available from http://www.comlaw.gov.au/Details/C2013C00022

Disability Investment Group. 2009. “The Way Forward: A New Disability Policy Framework for Australia.” Available from https://www.dss.gov.au/sites/default/files/documents/05_2012/dig_report_19oct09.pd f

Disability Services Act 1986, No. 129. 1986. Available from http://www.comlaw.gov.au/Details/C2013C00015

Dyck, I., P. Kontos, J. Angus, J., and P. McKeever. 2005. “The Home as a Site for LongTerm Care: Meanings and Management of Bodies and Spaces.” Health \& Place 11 (2): 173-185. doi:10.1016/j.healthplace.2004.06.001 
Eriksson, M., and B. Lindström. 2008. “A Salutogenic Interpretation of the Ottawa Charter.” Health Promotion International 23 (2): 190-199. doi: 10.1093/heapro/dan014

Felce, D. 1989. “The Andor Project: Staffed Housing for Adults with Severe or Profound Mental Handicaps.” Kidderminster: British Institute on Mental Handicap.

Foster, M., J. Fleming, and C. Tilse. 2007. “Council of Australian Governments’ (COAG) Initiative for Young People with Disability in Residential Aged Care: What are the Issues for Acquired Brain Injury?” Brain Impairment 8 (3): 312-322. Retrieved from http://search.informit.com.au.libraryproxy.griffith.edu.au/documentSummary; $\mathrm{dn}=980$ 019163043791;res=IELHEA

Foster, M., P. Henman, J. Fleming, C. Tilse, and R. Harrington. 2012. “The Politics of Entitlement and Personalisation: Perspectives on a Proposed National Disability Long-Term Care and Support Scheme in Australia.” Social Policy and Society 11 (3): 331-343. doi:10.1017/S147474641200005X

Harrell, R., E. Kassner, and C. Figueiredo. 2011. “Multigenerational Households are Increasing.” AARP Public Policy Institute Fact Sheet. Washington, DC: AARP Public Policy Institute.

Heywood, F. 2004. “Understanding Needs: A Starting Point for Quality.” Housing Studies 19(5): 709-726. doi:10.1080/0267303042000249161

Imrie, R. 2004. “Housing Quality, Disability and Domesticity.” Housing Studies 19 (5): 685690. doi:10.1080/0267303042000249143

Imrie, R. 2006. “Independent Lives and Relevance of Lifetime Homes.” Disability \& Society 21(4): 359-374. doi:10.1080/09687590600680152

Johnson, G., S. Parkinson, and C. Parsell. 2012. “Policy Shift or Program Drift? Implementing Housing First in Australia”. AHURI Final Report No. 184. Melbourne, Australia: Australian Housing and Urban Research Institute. 
Jonas, W. B., and R. A. Chez. 2004. “Toward Optimal Healing Environments in Health Care.” The Journal of Alternative and Complimentary Medicine 10 (S1): S1-S6. doi:10.1089/acm.2004.10.S-1

King, P. 1996. “The Limits of Housing Policy: A Philosophical Investigation.” London: Middlesex University Press.

Kozma, A., J. Mansell, and J. Beadle-Brown. 2009. “Outcomes in Different Residential Settings for People with Intellectual Disability: A Systematic Review.” American Journal on Intellectual and Developmental Disabilities 114 (3): 193-222. doi:10.1352/1944-7558-114.3.193

Kyle, T., and J. R. Dunn. 2008. "Effects of Housing Circumstances on Health, Quality of Life and Healthcare Use for People with Severe Mental Illness: A Review.” Health and Social Care in the Community 16 (1): 1-15. doi:10.1111/j.1365-2524.2007.00723x Lamontagne, M.-E., F. Poncet, E. Careau, M.-J. Sirois, and N. Boucher. 2013. “Life Habits Performance of Individuals with Brain Injury in Different Living Environments.” Brain Injury 27 (2): 135-144. doi:10.3109/02699052.2012.722253

Livable Housing Australia. 2012. “Livable Housing Design Guidelines (2nd ed).” Sydney, NSW: Livable Housing Australia.

Lord, J., and P. Hutchison. 2003. “Individualised Support and Funding: Building Blocks for Capacity Building and Inclusion.” Disability \& Society 18 (1): 71-86. doi:10.1080/713662196

MacKinnon, D., and C. Coleborne. 2003. “Introduction: Deinstitutionalisation in Australia and New Zealand.” Health and History 5 (2): 1-16. Available from http://www.jstor.org.libraryproxy.griffith.edu.au/stable/40111450

Mansell, J. 2009. “Foreword: The ‘Implementation Gap’ in Supported Accommodation for People with Intellectual Disabilities. In Group Homes for People with Intellectual 
Disabilities, edited by T. Clement and C. Bigby, 11-14. London, UK and Philadelphia, PA, USA: Jessica Kingsley Publishers.

Mansell, J., J. Beadle-Brown, B. Whelton, C. Beckett, and A. Hutchinson. 2008. “Effect of Service Structure Organization on Staff Care Practices in Small Community Homes for People with Intellectual Disabilities.” Journal of Applied Research in Intellectual Disabilities 21 (5): 398-413. doi:10.1111/j.1468 - 3148.2007.00410.x

Mansell, J., D. Felce, D. Jenkins, U. de Knock, and S. Toogood. 1987. “Developing Staffed Housing for People with Mental Handicaps.” Tunbridge Wells, UK: Costello.

Morris, J. 2004. “Independent Living and Community Care: A Disempowering Framework.” Disability \& Society 19 (5): 427-442. doi:10.1080/0968759042000235280

Muenchberger, H., Ehrlich, C., Kendall, E., \& Vit, M. (2012). Experience of place for young adults under 65 years with complex disabilities moving into purpose-built residential care. Social Science \& Medicine, 75, 2151-2159.

doi:10.1016/j.socscimed.2012.08.002

Nalder, E., J. Fleming, M. Foster, P. Cornwell, C. Shields, and A. Khan. 2012. “Identifying Factors Associated with Perceived Success in the Transition from Hospital to Home after Brain Injury.” The Journal of Head Trauma Rehabilitation 27 (2): 143-153. doi:10.1097/HTR.0b013e3182168fb1

National Disability Insurance Scheme Act 2013, No. 20 2013. Available from http://www.comlaw.gov.au/Details/C2014C00386

NSW Department of Ageing, Disability and Home Care. 2009. “Exploring and Implementing Person Centred Approaches: A Guide for NSW Community Participation Program Service Providers.” Available from http://www.adhc.nsw.gov.au/_data/assets/file/0006/228291/ExploringandImplementi ngPersonCentredApproachesUpd.pdf 
Office of the Public Advocate - Queensland. 2005. "Housing Design for All: Universal Housing Design in Queensland (Issue Paper 3).” Brisbane, QLD: Office of the Public Advocate - Queensland.

Ownsworth, T., M. Turpin, G. Carlson, and J.-A. Brennan. 2004. “Perceptions of Long-Term Community-Based Support Following Severe Brain Injury.” Brain Impairment 5 (1): 53-66. doi:10.1375/brim.5.1.53.35407

Parker, C., S. Barnes, K. McKee, K. Morgan, J. Torrington, and P. Tregenza. 2004. “Quality of Life and Building Design in Residential and Nursing Homes for Older People.” Ageing and Society 24 (6): 941-962. doi: 10.1017/S0144686.X04002387

Parker, S., and K. R. Fisher. 2010. “Facilitators and Barriers in Australian Disability Housing Support Policies: Using a Human Rights Framework.” Disability Studies Quarterly 30(3). Available from http://dsq-sds.org/article/view/1283/1310 PricewaterhouseCoopers (PwC). 2011. “Disability Expectations: Investing in a Better Life, a Stronger Australia.” Available from http://www.pwc.com.au/industry/government/assets/disability-in-australia.pdf Quarterly Brain Injury Services Meeting (QBISM) Group (2013). A comprehensive service system for Queenslanders with brain injury: Positioning paper. Retrieved from http://synapse.org.au/media/89778/qbism_position_paper_-_final_september_12.pdf

Queensland Action for Universal Housing Design. n.d. "Submission in Response to the Draft Report by Productivity Commission Inquiry into Caring for Older Australians”. Available from http://www.pc.gov.au/inquiries/completed/agedcare/submissions/subdr640.pdf

Robst, J., R. Deitz, and K. McGoldrick. 1999. “Income Variability, Uncertainty and Housing Tenure Choice.” Regional Science and Urban Economics 29 (2): 219-229. doi:10.1016/S0166-0462(98)00031-3 
Sanderson, H., J. Thompson, and J. Kilbane. 2006. “The Emergence of Person-Centred Planning as Evidence-Based Practice.” Journal of Integrated Care 14 (2): 18-25. doi:10.1108/147690182006000014

Saugeres, L. 2011. “(Un)accommodating Disabilities: Housing, Marginalization and Dependency in Australia.” Journal of Housing and the Built Environment 26 (1): 115.doi:10.1007/s10901-010-9201-x

Schulz, A., and M. E. Northridge. 2004. "Social Determinants of Health: Implications for Environmental Health Promotion.” Health Education \& Behavior 31 (4): 455-471. doi:10.1177/1090198104265598

Sloan, S., L. Callaway, D. Winkler, K. McKinley, and C. Ziino. 2012. “Accommodation Outcomes and Transitions Following Community-Based Intervention for Individuals with Acquired Brain Injury.” Brain Impairment 13 (1): 24-43. doi:10.1017/Brlmp.2012.5

State of Victoria, Department of Human Services. 2003. “Responding to People with Multiple and Complex Needs Project: Client Profile Data and Case Studies Report.” Melbourne, VIC: Operations Division, Victorian Government Department of Human Services.

Taleporos, G., D. Craig, M. Brown, C. McNamara, and S. Forbes. 2013. “Housing and Support for Younger People with Disabilities Transitioning to Independent Living: Elements for Success in the Design and Implementation of DisabilityCare Australia, a National Disability Insurance Scheme.” Melbourne, Victoria: Youth Disability Advocacy Service.

Tsemberis, S., L. Gulcur, and M. Nakae. 2004. “Housing First, Consumer Choice, and Harm Reduction for Homeless Individuals with a Dual Diagnosis.” American Journal of Public Health 94 (4): 651-656. doi:10.2105/AJPH.94.4.651 
Ulrich, R. S. 2000. “Evidence Based Environmental Design for Improving Medical Outcomes.” Paper presented at the Healing by Design: Building for Healthcare in the 21st Century National Conference, McGill University Health Center, Montreal, Canada, September 2000.

Ulrich, R. S. 2006. “Essay: Evidence-Based Health-Care Architecture.” The Lancet 368: S38S39. doi:10.1016/S0140-6736(06)69921-2

United Nations. 2006. “Convention on the Rights of Persons with Disabilities.” Available from www.un.org/disabilities/convention/conventionfull.shtml

Victorian Coalition of ABI Service Providers Inc. 2014. "Submission to the Inquiry into Affordable Housing: Response to the Senate Economics References Committee.” Available from http://webcache.googleusercontent.com/search?q=cache:hyBoGTqd5S4J:www.aph.g ov.au/DocumentStore.ashx\%3Fid\%3Db408c946-4a2f-4549-9e2f60a1592ae858\%26subId\%3D206884+\&cd=1\&hl=en\&ct=clnk\&gl=au

Wagemakers, A., L. Vaandrager, M. A. Koelen, H. Saan, and C. Leeuwis. 2010. “Community Health Promotion: A Framework to Facilitate and Evaluate Supportive Social Environments for Health.” Evaluation and Program Planning 33 (4): 428-435. doi:10.1016/j.evalprogplan.2009.12.008

Wiesel, I. 2011. “Allocating Homes for People with Intellectual Disability: Needs, Mix and Choice.” Social Policy \& Administration 45 (3): 280-298. doi:10.1111/j.14679515.2011.00769.x

Wiesel, I., and R. Fincher. 2009. “The Choice Agenda in Disability Housing Provision.” Housing Studies 24 (5): 611-627. doi:10.1080/02673030903086790 
Williamson, M. 2006. “Innovative Accommodation Support for Western Australians with a Disability: A Discussion Paper.” Available from http://www.ideaswa.net/accommodation-think-tank.html

Winkler, D., L. Farnworth, S. Sloan, and T. Brown. 2011. “Moving from Aged Care Facilities to Community-Based Accommodation: Outcomes and Environmental Factors.” Brain Injury 25 (2): 153-168. doi:10.3109/02699052.2010.541403

Winkler, D., L. Farnworth, S. Sloan, K. Stringer, and L. Callaway. 2011. “Young People in Nursing Homes: White Paper.” Melbourne, Victoria: Summer Foundation Ltd and Monash University.

Wister, A. V. 2005. “The Built Environment, Health, and Longevity.” Journal of Housing for the Elderly 19 (2): 49-70. doi:10.1300/J081v19n02_04

Young People in Nursing Homes National Alliance and Monash University. 2014. "Shaping the Future Today: Transforming Housing Policy for Australians with Disability." Available from http://www.ypinh.org.au/images/stories/ypinhna-housing-policydiscussion.pdf 